\section{SECURITY ASSESSMENT \\ OF POWER SYSTEMS \\ INCLUDING ENERGY STORAGE}

Progress Report
for Period April 1, 1978 - June 30, 1978

\section{Energy Systems Simulation Laboratory School of Electrical Englneering Purdue University West Lafayette, Indiana 47907}

- NOTICE

This was prepsed as an account of work This report was prepared as an accent. Neither the United States nor the United States Department of Energy, nor any of their employees, nor any or that contractors, subcontractors, or their employes. makes any warranty, express or implied, or assumes anyleteness liability or responsibility for the accuracy, completenes or usefulness of any information, apparatus, product or or usefuldisclosed, or represents that its use would not process disclosed, or inged rights.

July 1978

Prepared For

THE UNITED STATES DEPARTMENT OF ENERGY UNDER CONTRACT NO. EC-77-S-02-4206.A000 


\section{DISCLAIMER}

This report was prepared as an account of work sponsored by an agency of the United States Government. Neither the United States Government nor any agency Thereof, nor any of their employees, makes any warranty, express or implied, or assumes any legal liability or responsibility for the accuracy, completeness, or usefulness of any information, apparatus, product, or process disclosed, or represents that its use would not infringe privately owned rights. Reference herein to any specific commercial product, process, or service by trade name, trademark, manufacturer, or otherwise does not necessarily constitute or imply its endorsement, recommendation, or favoring by the United States Government or any agency thereof. The views and opinions of authors expressed herein do not necessarily state or reflect those of the United States Government or any agency thereof. 


\section{DISCLAIMER}

Portions of this document may be illegible in electronic image products. Images are produced from the best available original document. 
CONTRACT ACTIVITY

The principal investigators have devoted $50 \%$ of their workload to this contract during this quarter. This is expected to continue through the remainder of the year. 
TABLE OF CONTENTS

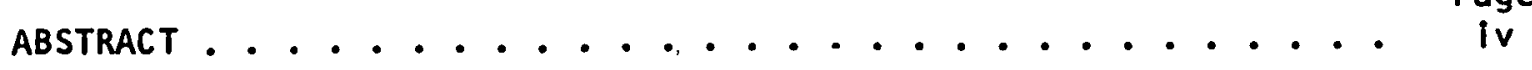

SECTION 1 - VERIFICATION OF SIMPLIFIED MODEL FOR CURRENT-FED

FORCE-COMMUTATED CONVERTER ........... I

1.1 Simplified Models ............. 1

1.2 Computer Simulations............ 5

1.3 Computer Studies. ............ 6

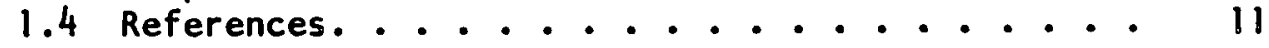

SECTION 2 - POWER SYSTEM IDENTIFICATION. .......... 18

2.1 Hardware Noise Generators .......... 18

2.2 Least Squares Estimation. .......... 18

2.3 The Yule Walker Equations......... 19

SECTION 3 - EQUIVALENT SYSTEM MODEL FOR BPA INDUCTOR-

CONVERTER DAMPING STUDIES. ........... 21

3.1 BPA Equivalent System Representation. . . . . 21

3.2 Computer Study-BPA Equivalent System. ...... 25

3.3 Conclusions and Work Schedule-BPA Project.... 28 
ABSTRACT

\section{Energy Storage}

Work has continued on the verification of the simplified model of a force-commutated inductor-converter (IC) unit. This simplified analytical model will be useful in power system studies involving the control applications of magnetic energy storage devices. Computer simulations of a three-bus power system equivalent with both the simplified and a detailed converter representation were compared for verification of the simplified IC model.

Work has also continued on the special task involving the application of small IC units for system damping. The BPA equivalent system has been simulated and a comparison has been made with field results taken during the Dynamic Brake test. The IC unit has been incorporated into this simulation and system damping studies have been performed.

\section{Identification}

A set of DIBN noise generators has been constructed from TTL logic packages, and are now used in system simulations. The limitations of least squares schemes for estimation of system parameters have been established. A study is being made of the use of the Yule-Walker equations for parameter calculation from an autocorrelation estimate. 


\section{SECTION I}

\section{VERIFICATION OF SIMPLIFIED MODEL FOR CURRENT-FED}

FORCE-COMMUTATED CONVERTER

In a previous progress report c00-4206-2 the derivation of simplified analytical expressions was described in detall for a current-fed forcecommutated converter (CFFCC). During the current perlod of investigation, these expressions were used to formulate a simplified power system model of a superconducting inductor-converter (IC) unit. This simplified forcecommutated IC model, which neglects converter harmonics, is suitable for power system control studies. Computer simulations of a three-bus power system equivalent with both the simplified and a detalled. CFFCC representation were compared for verification of the simplified IC model. Sample results of the simulation study are included in this report.

\subsection{Simplified Models}

The simplified model developed here for a 12-pulse CFFCC is based on ac reference frame theory and is similar to previous modeling described in progress report c00-4206-1 for a line-commutated converter. The simplified converter model can be used directly with the equivalent circuit of a superconducting magnet in order to form an analytical model for force-commutated ic units. The converter model is related directly to the ac bus supplying the converter, and therefore, can be conveniently used in a system of arbitrary configuration. In developing the simplified model, it is assumed that ac bus voltages are balanced and sinusoidal, and the direct current is constant. The bus voltages are represented in a synchronously rotating reference frame by the quantities $v_{q}$ and $v_{d}$. 

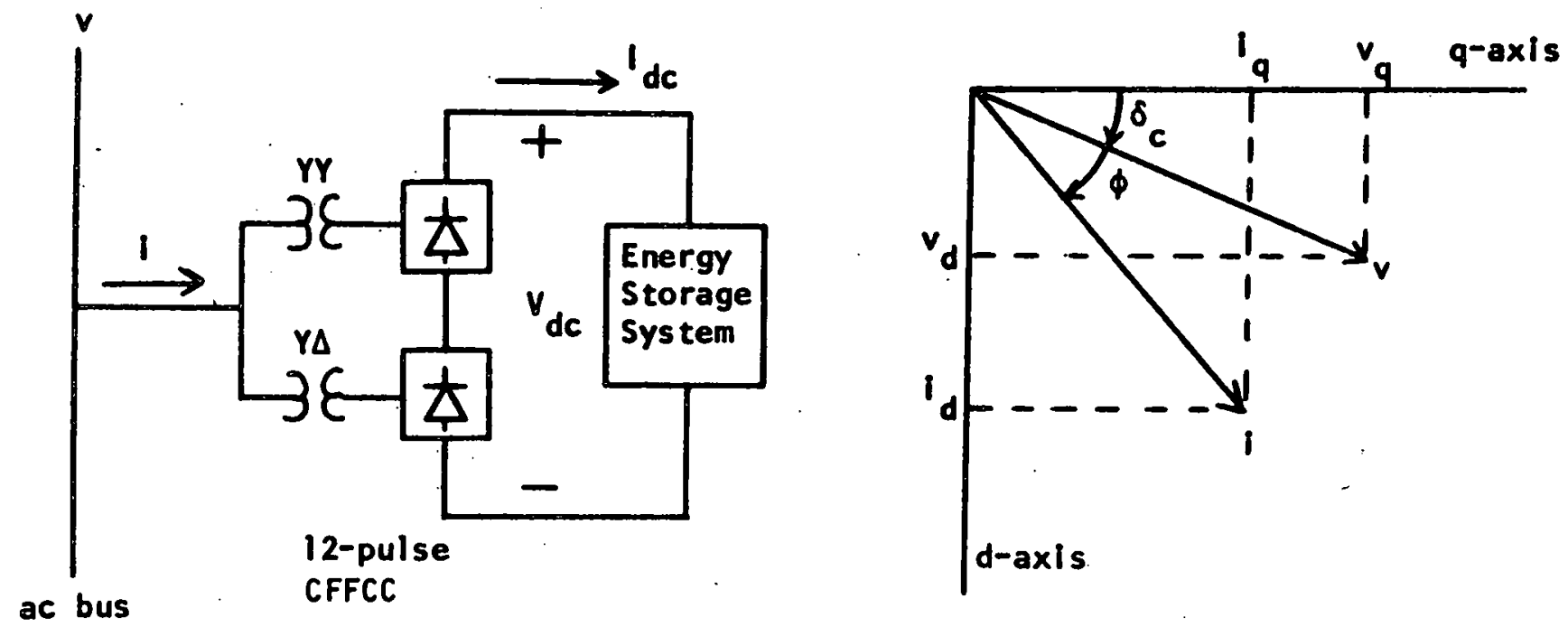

Fig. I.I Simplified Model Representations.

From Fig.l. It is clear that the amplitude of the bus voltage, defined as the crest phase-to-neutral voltage, is given by

$$
E_{m}=\sqrt{v_{q}^{2}+v_{d}^{2}}
$$

and

$$
\delta_{c}=\tan ^{-1}\left(\frac{v_{d}}{v_{q}}\right),-180^{\circ}<\delta_{c}<180^{\circ}
$$

For a 12-pulse converter, the crest fundamental line current into the converter is well-approximated by the expression [1]

$$
I_{m}=\frac{4 \sqrt{3}}{\pi} I_{d c}
$$

where $I_{d c}$ is the converter direct current. If converter losses are neglected, the fundamental power factor is given by

$$
\cos \phi=\frac{\pi V_{d c}}{6 \sqrt{3} E_{m}}, \quad-180^{\circ}<\phi<180^{\circ}
$$


where $v_{d c}$ is the converter direct voltage and $\phi$ is the angle that the fundamental converter current lags the bus voltage. Equation (4) is valid for both rectifier and inverter operation. From Fig.l.lit is also evident that

$$
\begin{aligned}
& i_{q}=i_{m} \cos \left(\delta_{c}+\phi\right) \\
& i_{d}=i_{m} \sin \left(\delta_{c}+\phi\right)
\end{aligned}
$$

The direct voltage output of the 12-pulse converter is represented in the simplified model by its average value. For detalls see progress report C00-4206-2.

$$
V_{d c}=\frac{6 \sqrt{3}}{\pi} E_{m} \cos (\alpha+\theta)-\frac{18}{\pi} \sqrt{\frac{X_{l}}{X_{c}}} E_{m} \sin (\alpha+\theta)
$$

Also we have the relation

$$
x_{c} I_{d c} \theta+3 \sqrt{3} E_{m} \sin (\alpha+\theta)-\sqrt{3 x_{l} X_{c}} I_{d c}=0
$$

where $\alpha$ is the gating delay (control) angle, $X_{\ell}$ is the per phase leakage reactance of each transformer, $x_{c}$ is the commutating capacitor reactance, and $\theta$ is the capacitor discharging angle. The converter control angle $\alpha$ is in general a function of several system variables, that is

$$
\alpha=F\left(V_{d c}, I_{d c}, E_{m}, E_{r e f}, E_{e x t}\right)
$$

where $E_{\text {ref }}$ may be a constant current reference or a constant power reference, and $E_{\text {ext }}$ is an external modulation signal for some special control purpose. For control studies, a superconducting magnet can be modeled as simply a linear inductance $[2,3]$, so that

$$
v_{d c}=L \frac{d}{d t} I_{d c}
$$

The resulting simplified model for a force-commutated iC unit consists of a simultaneous solution of Eqs. (1) - (10). Figure 1.2shows the solution flow used in the model. For the study of a specific system or application, it is clear that Eq. (9) would be more explicitly defined. 


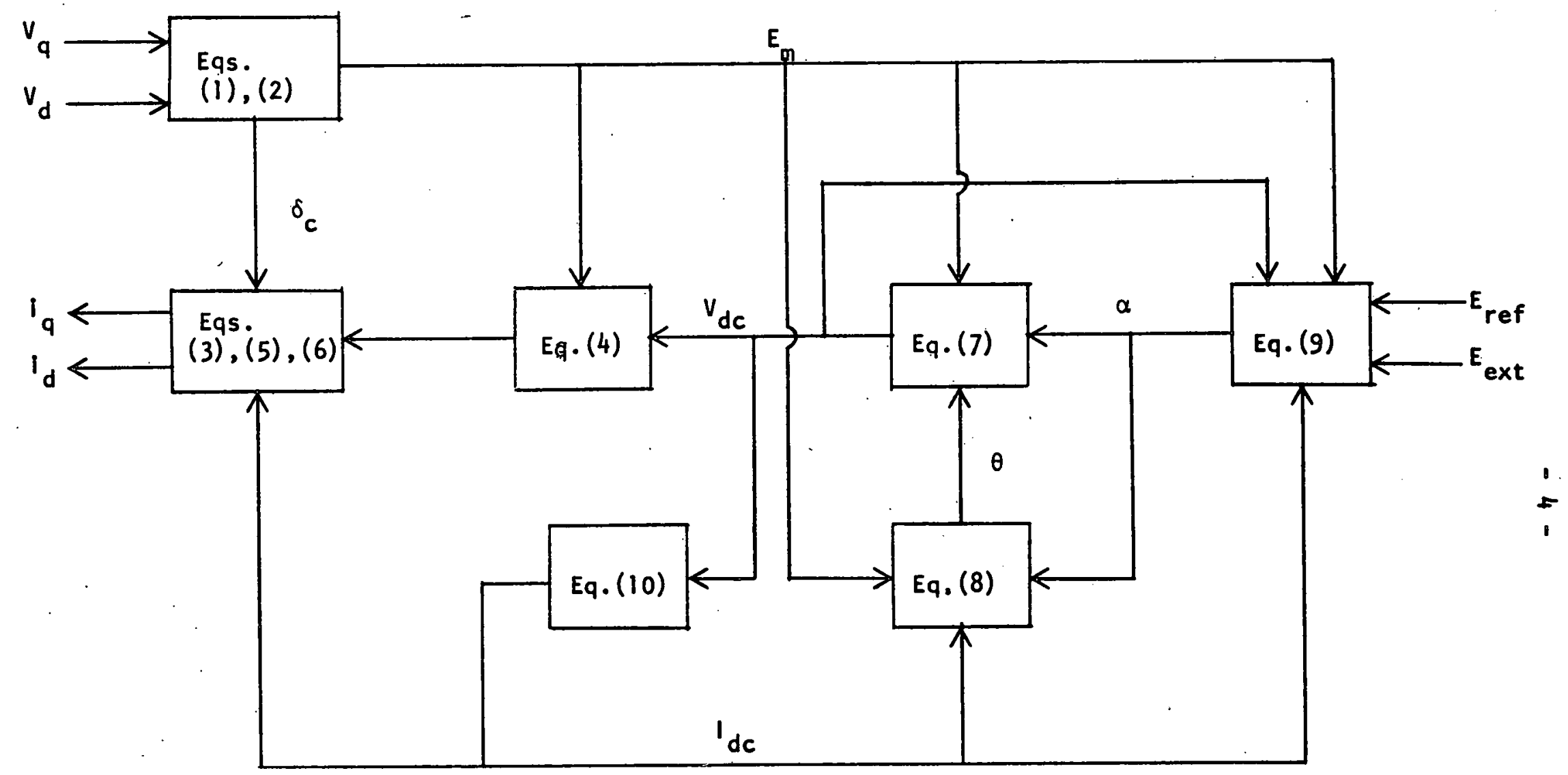

Fig. 1.2 Block Diagram of Simplified Model. 


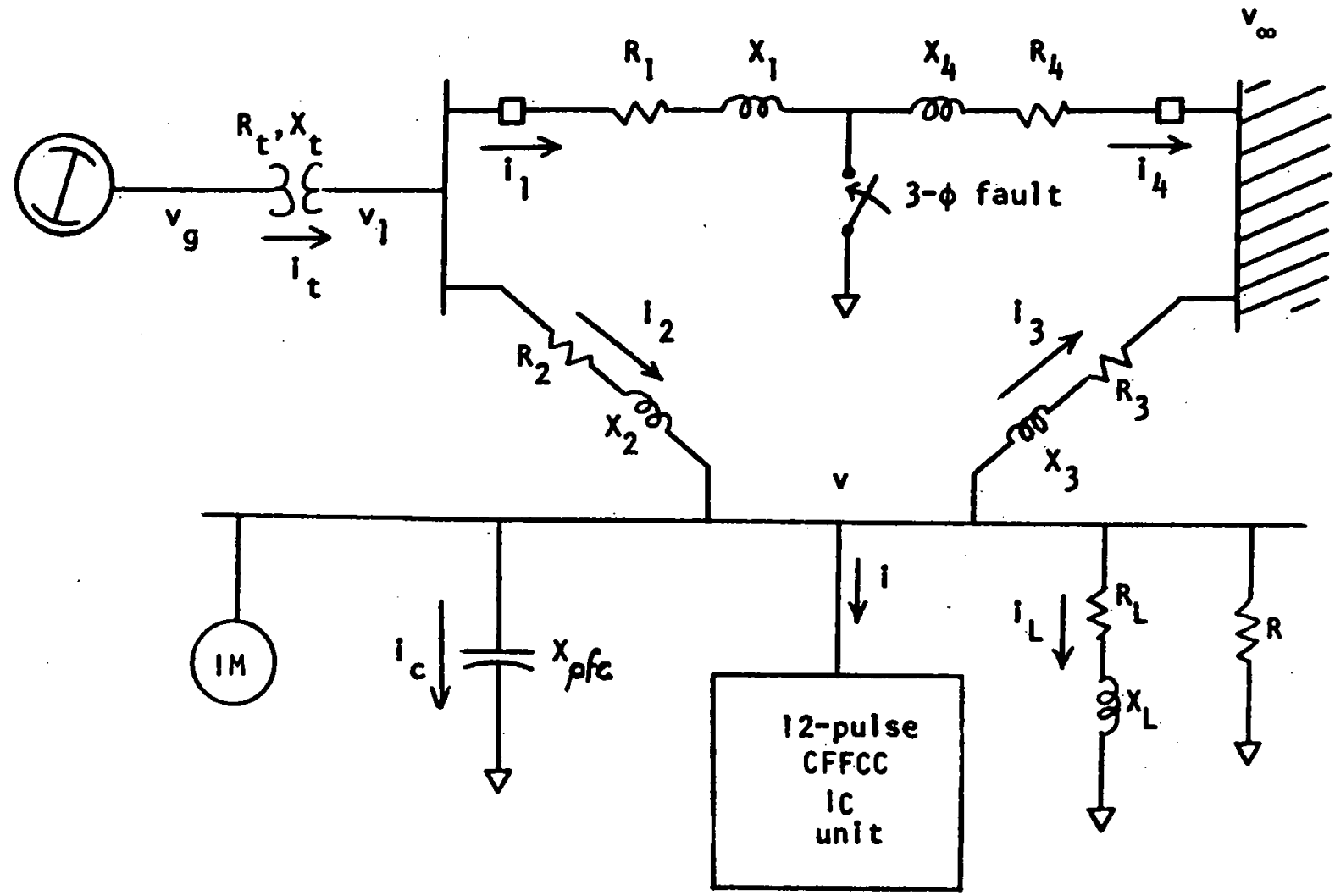

Fig. 1.3 Power System Simulated

\subsection{Computer Simulations}

For purposes of verification of the simplified force-commutated IC model, two hybrid computer simulations were developed for the one-machine/ Infinite bus system shown in Fig. 1.3. In one simulation, reference frame theory is used to reduce the system to a simplified representation which is compatible with the simplified model of the storage unit. The other computer simulation is a detailed three-phase representation of the system, which includes an individual valve representation of the converter. In both simulations, Park's equations are used to represent the synchronous machine. An IEEE Type 1 excitation system is used with the machine simulation. In the simplified simulation of the system the transmission 
network, loads, and infinite bus are represented in the synchronousiy rotating reference frame, as is the simplified model of the IC unit. The syrichronous machine is represented in a reference frame fixed in the rotor.

The control system used in both simulations of the IC unit is basically a power control, in which a regulator signal $e_{c}$ is generated by the expression

$$
e_{c}=\frac{\pi P_{\text {ref }}}{6 \sqrt{3} I_{d c}}-\frac{K}{s} v_{d c}
$$

In the detalled simulation the converter gating pulses are determined by the Inverse cosine comparator method, therefore the control angle $\alpha$ is related to the regulator signal by

$$
\alpha=\cos ^{-1}\left(\frac{e_{c}}{E_{m}}\right)
$$

Since the CFFCC has no inherent constraints on $\alpha$, symmetrical regulator limits were chosen corresponding to a preset minimum control angle $\alpha_{0}$, that is

$$
-E_{m} \cos \alpha_{0} \leq e_{c} \leq E_{m} \cos \alpha_{0}
$$

The power reference. is modulated with a feedback measurement of $\Delta \omega_{r}$, the change in machine speed from synchronous speed, $\omega_{e^{*}}$

$$
P_{\text {ref }}=K_{m} \Delta w_{r}
$$

In the simplified simulation of the IC unit, equations (11)-(14) define the relationship given in equation (9).

\subsection{Computer Studies}

Several computer studies were made with the system described, for comparison of the simplified and the detalled representations. The studies Included In this report were made for an equivalent 1000 MVA machine, and a 
$10 \mathrm{MW}$ and $70 \mathrm{MW}$ IC unit. The nominal per unit parameters of the machine, transmission network, and the load, on the power base of the machine, are listed below.

Machine

$H=2.95 \mathrm{sec}$

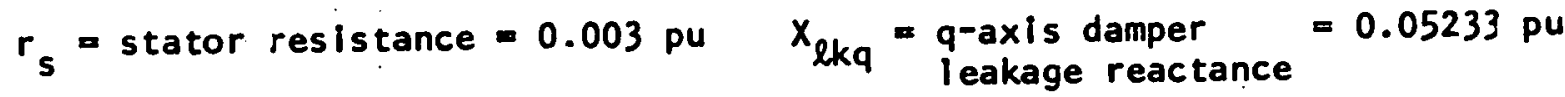

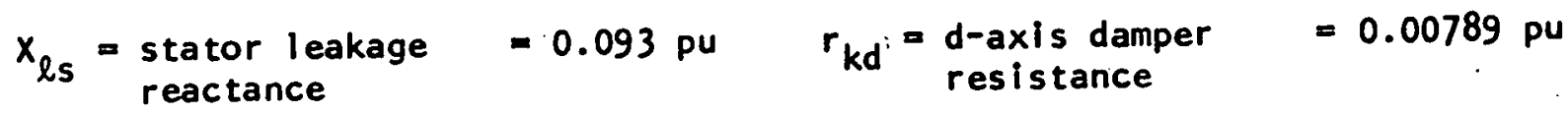

$$
\begin{aligned}
& r_{f}=\text { field resistance }=0.00082 \mathrm{pu} x_{\ell k d}=\begin{array}{l}
\text { d-axis damper } \\
\text { leakage reactance }
\end{array}=0.025 \mathrm{pu} \\
& X_{\ell f}=\begin{array}{l}
\text { field leakage } \\
\text { reactance }
\end{array} \quad=0.10746 \mathrm{pu} \quad X_{\mathrm{mq}}=\underset{\text { ing reactance }}{\text { ing }}=1.12 \mathrm{pu} \\
& r_{k q}=\begin{array}{l}
q \text {-axis damper } \\
\text { resistance }
\end{array} \quad=0.00759 \mathrm{pu} \quad x_{m d}=\underset{\text { ing reactance }}{\mathrm{d} \text {-axis magnetiz- }}=1.44 \mathrm{pu}
\end{aligned}
$$

Machine Excltation (IEEE Type 1)

$$
\begin{array}{lll}
K_{A}=50 & K_{F}=0.013 & V_{\text {ref }}=1.0 \mathrm{pu} \\
T_{A}=0.02 \mathrm{sec} & T_{F}=0.38 \mathrm{sec} & S_{E M A X}=0.19 \mathrm{pu} \\
K_{E}=-0.02 & V_{R M A X}=1.0 \mathrm{pu} & S_{E M I N}=0.08 \mathrm{pu} \\
T_{E}=0.08 \mathrm{sec} & V_{R M I N}=-1.0 \mathrm{pu} &
\end{array}
$$

Machine Transformer

$$
R_{t}=0.01 \mathrm{pu} \quad x_{t}=0.1 \mathrm{pu}
$$

Transmission Network

$$
\begin{array}{lll}
v_{\infty}=1.0 \mathrm{pu} & R_{2}=0.01 \mathrm{pu} & R_{3}=0.05 \mathrm{pu} \\
R_{1}=R_{4}=0.03 \mathrm{pu} & x_{2}=0.1 \mathrm{pu} & x_{3}=0.5 \mathrm{pu} \\
x_{1}=x_{4}=0.3 \mathrm{pu} & &
\end{array}
$$


Static Loads

$$
R_{L}=4 \mathrm{pu} \quad X_{L}=2 \mathrm{pu} \quad R=20 \mathrm{pu}
$$

Induction Motor Loud

$$
\begin{array}{ll}
r_{s}=0.003 \mathrm{pu} & r_{r}^{\prime}=0.00759 \mathrm{pu} \\
x_{l s}=0.093 \mathrm{pu} & x_{\ell r}^{\prime}=0.0375 \mathrm{pu} \\
x_{m}=1.435 \mathrm{pu} & H=1.0 \mathrm{pu}
\end{array}
$$

The nominal parameters associated with the IC unit, on the power base of the converter, are given below. The inductance of the superconducting magnet was determined from information in a previous investigation [4].

PFC Capacitor

$$
x_{p f c}=0.75 \mathrm{pu}
$$

Converter

$$
x_{\ell}=0.2 \mathrm{pu} \quad x_{c}=70 \mathrm{pu}
$$

Converter Control

$$
\alpha_{0}=6^{\circ} \quad K_{m}=0.2652 \mathrm{pu} \quad K=1 \mathrm{pu}
$$

Superconducting Magnet

$$
\mathrm{L}=43.77 \mathrm{pu}
$$

The per unit system for representing the parameters and variables assoclated with the IC unit, uses the rated value of $E_{m}$ as a base voltage, and the base impedance is computed from

$$
z_{b}=\frac{3}{2} \frac{\left(E_{m} k v\right)^{2}}{\text { total converter MVA }}
$$

This means that the leakage reactance of each converter transformer, on its Own base, is actually $1 / 2$ of that given above (i.e., $x_{l}=0.1$ pu on each transformer base). Also, the rated direct voltage and current of the 12pulse converter become approximately $3 \mathrm{pu}$ and $0.5 \mathrm{pu}$, respectively, in this per unit system. 
Figures $1.4-1.9$ are sample results from the simulation studies performed. In each case waveforms from the simplified representation are compared with corresponding results taken from the detalled representation. The variables recorded are listed below.

$T_{e}=$ Machine Electrical Torque

$$
\begin{aligned}
\frac{\Delta \omega_{r}}{\omega_{e}} & =\text { Ratio of Machine Speed Change to Synchronous Speed } \\
\delta & =\text { Machine Rotor Angle } \\
E_{x} & =\text { Machine Excitation } \\
v_{g a} & =\text { Phase 'a' Machine Terminal Voltage } \\
E_{g m} & =\text { Crest Machine Terminal Voltage } \\
v_{a} & =\text { Phase 'a' Converter Bus Voltage } \\
E_{m} & =\text { Crest Converter Bus Voltage } \\
v_{d c} & =\text { Converter Direct Voltage } \\
I_{d c} & =\text { Converter Direct Current }
\end{aligned}
$$

The waveforms shown are system responses to a three-phase fault at the middle of the transmission line between the machine bus and the infinite bus. The fault is cleared after $0.25 \mathrm{sec}$. The electrical transients shown on the recordings clearly mark the occurrence of the fault and its subsequent clearing. For simplicity, the prime mover torque was held constant during the entire transient shown in each recording. Power Modulation of the CFFCC unit was performed at both leading and lagging converter power factors by changing the polarity of the control angle $\alpha$. A leading power factor causes the converter to supply reactive power to the system, a condition not possible with a line-commutated converter. 
Figures 1.4-1.7 show the fault responses of the nominal system when the $10 \mathrm{MW}$ and $70 \mathrm{MW} \mathrm{IC} \mathrm{units} \mathrm{are} \mathrm{modulated.} \mathrm{In} \mathrm{each} \mathrm{case} \mathrm{the} \mathrm{prefault} \mathrm{state}$ of the IC unit was held at zero direct voltage and rated direct current. Figures 1.4 and 1.5 were taken for the $10 \mathrm{MW}$ unit. Comparing the simplified and detailed waveforms, it is apparent that the corresponding results show nearly exact agreement. Due to the small size of the IC unit relative to the machine capacity, the damping provided by the unit is noticeable but not dramatic. Figures 1.6 and 1.7 were taken for the $70 \mathrm{MW}$ unit operated with the nominal system. For this stronger unit, the responses using the simplifled model are again nearly the same to those obtained using the detailed representation. The results also show that the $70 \mathrm{MW}$ IC unit provides considerable damping to the system; some benefit is even obtained on the first few swings. Flgures 1.8 and 1.9 were also taken for the 70 MW unit, but the control angle limit was changed to $\alpha_{0}=25^{\circ}$ to allow the CFFCC to supply more reactive power to the system. The results shown in these recordings further verify the simplified model. 
1.4 References

1. E. W. Kimbark, Direct Current Transmission, Vol. 1, WileyIntersclence, 1971 .

2. 'Wisconsin Superconductive Energy Storage Project," Vol. I, University of Wisconsin, July 1974.

3. "Wisconsin Superconductive Energy Storage Project," Vol. 2, University of Wisconsin, January 1976.

4. W. V. Hassenzahl and H. J. BoenIg, "Superconducting Magnetic Energy Storage," World Electrotechnical Congress, Moscow, USSR, June 1977. 


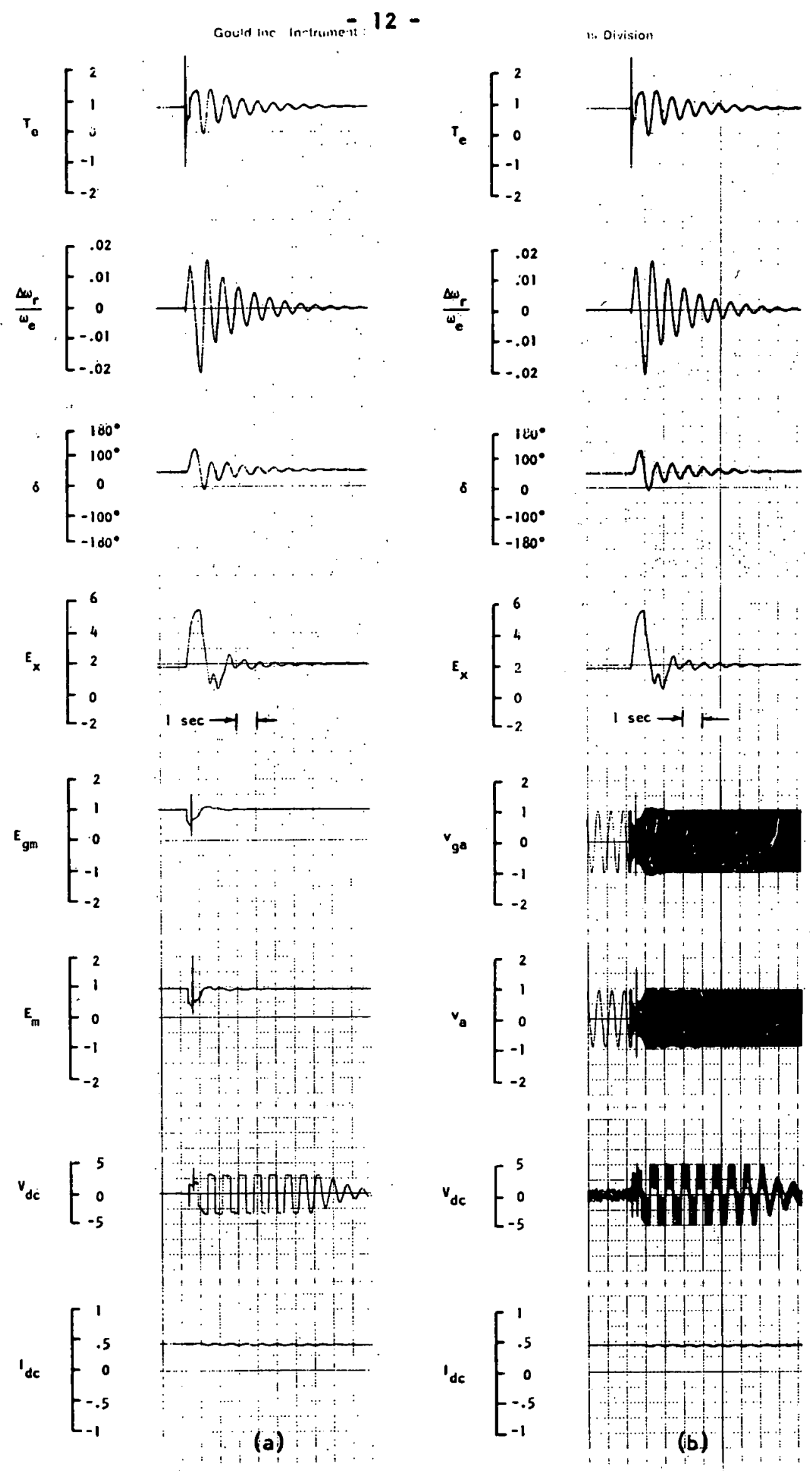

Fig.1.4 Fault Response of Nominal System with Modulated 1.0MW IC unit, Lagging PF: (a) Simplified Model, (b) Detailed Simulation. 
Te $\left[\begin{array}{c}2 \\ 1 \\ 0 \\ -1 \\ -2\end{array}\right.$

$\frac{\omega_{r}}{\omega_{e}}\left[\begin{array}{c}.02 \\ .01 \\ 0 \\ -.01 \\ -.02\end{array}\right.$

$\delta\left[\begin{array}{c}180^{\circ} \\ 100^{\circ} \\ 0 \\ -100^{\circ} \\ -180^{\circ}\end{array}\right.$

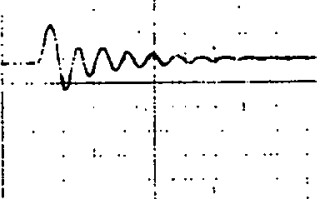

$E_{x}\left[\begin{array}{c}6 \\ 4 \\ 2 \\ 0 \\ -2\end{array}\right.$

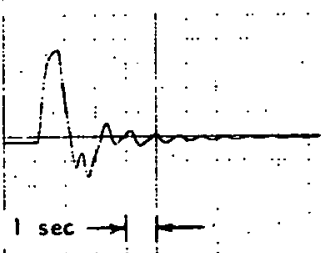

$E_{g m}\left[\begin{array}{c}2 \\ 1 \\ 0 \\ -1 \\ -2\end{array}\right.$

$E_{\mathrm{m}}\left[\begin{array}{c}2 \\ 1 \\ 0 \\ -1 \\ -2\end{array}\right.$

$v_{d c}\left[\begin{array}{c}5 \\ 0 \\ -5\end{array}\right.$
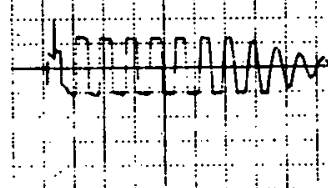

$\operatorname{doc}\left[\begin{array}{c}1 \\ .5 \\ 0 \\ -.5 \\ -1\end{array}\right.$

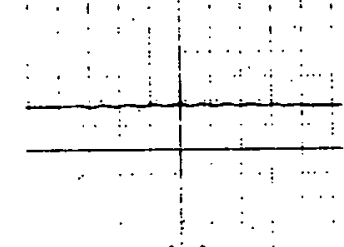

(b) re $\left[\begin{array}{c}2 \\ 1 \\ 0 \\ -1 \\ -2\end{array}\right.$

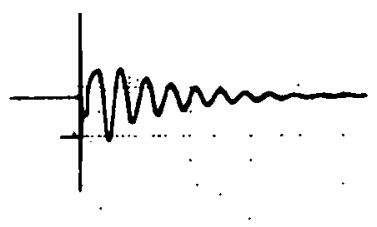

$\frac{\omega_{r}}{\omega_{c}}\left[\begin{array}{c}.02 \\ .01 \\ 0 \\ -.01 \\ -.02\end{array}\right.$

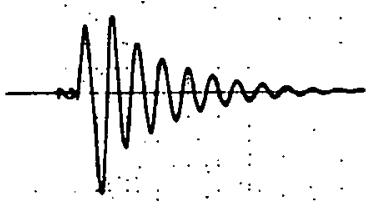

$\delta\left[\begin{array}{c}180^{\circ} \\ 100^{\circ} \\ 0 \\ -100^{\circ} \\ -180^{\circ}\end{array}\right.$

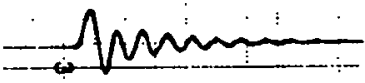

E $\quad\left[\begin{array}{c}6 \\ 4 \\ 2 \\ 0 \\ -2\end{array}\right.$

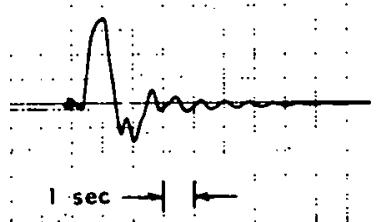

$\checkmark\left[\begin{array}{c}2 \\ 1 \\ 0 \\ -1 \\ -2\end{array}\right.$

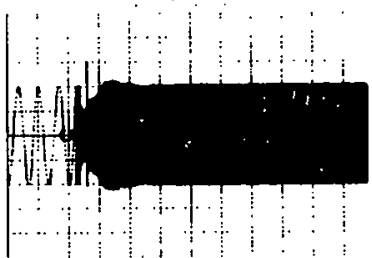

$\checkmark\left[\begin{array}{r}2 \\ 1 \\ 0 \\ -1 \\ -2\end{array}\right.$

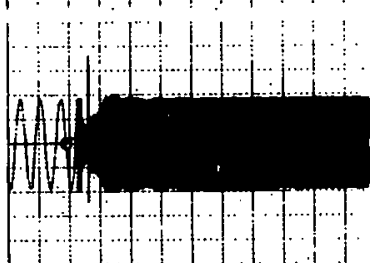

$v_{\text {de }}\left[\begin{array}{c}5 \\ 0 \\ -5\end{array}\right.$

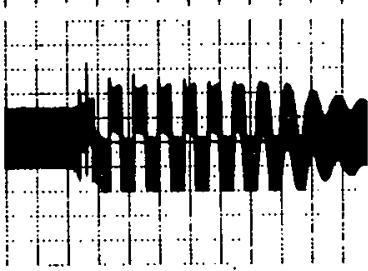

Ide $\left[\begin{array}{c}1 \\ .5 \\ 0 \\ -.5 \\ -1\end{array}\right.$

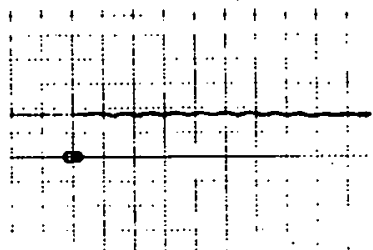

(b)

Fig.1.5 Fault Response of Nominal System with Modulated IOMW IC unit, Leading PF: (a) Simplified Model, (b) Detailed Simulation. 

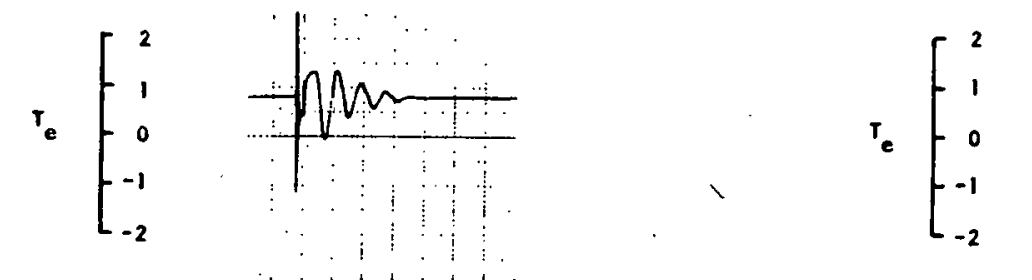

$\frac{\Delta \omega_{r}}{\omega_{e}}\left[\begin{array}{c}.02 \\ .01 \\ 0 \\ -.01 \\ -.02\end{array}\right.$

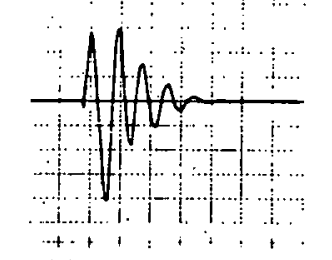

$\frac{\Delta \omega_{r}}{\omega_{e}}\left[\begin{array}{c}.02 \\ .01 \\ 0 \\ -.01 \\ -.02\end{array}\right.$

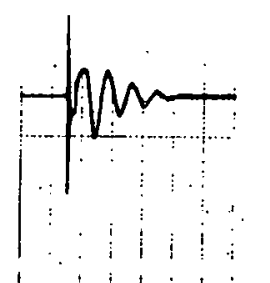

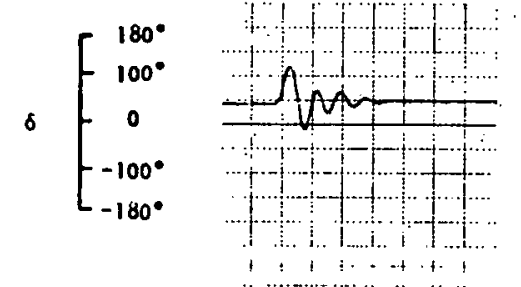
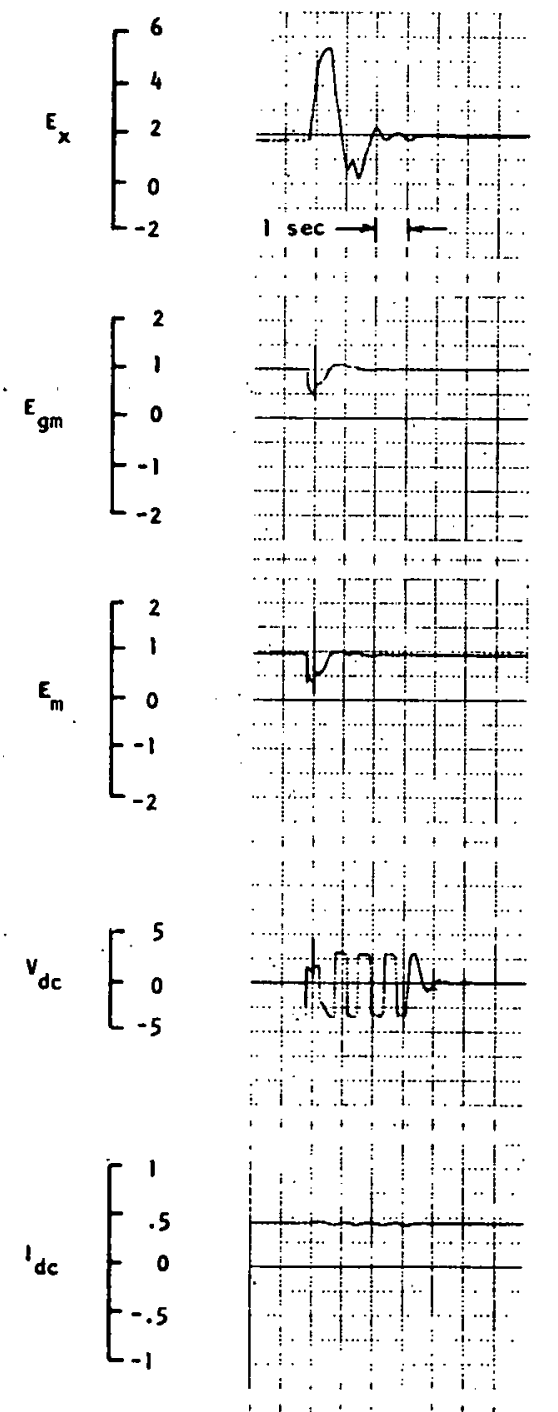
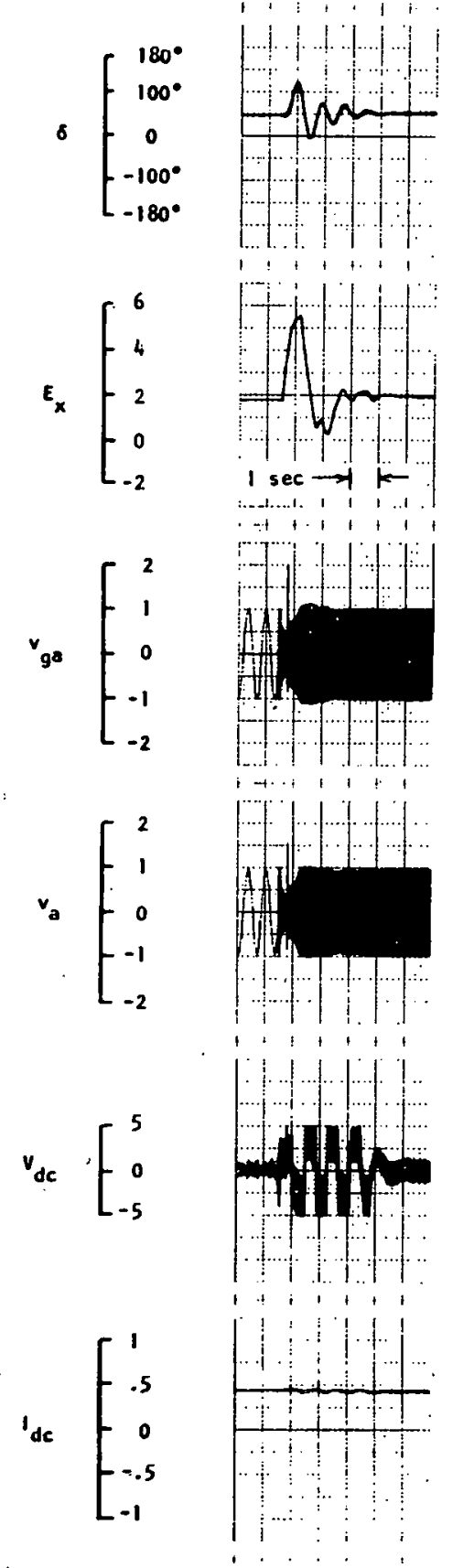

Fig. 1.6 Fault Response of Nominal System with Modulated 70 MW IC Unit, Lagging PF: (a) Simplified Model, (b) Detailed Simulation. 

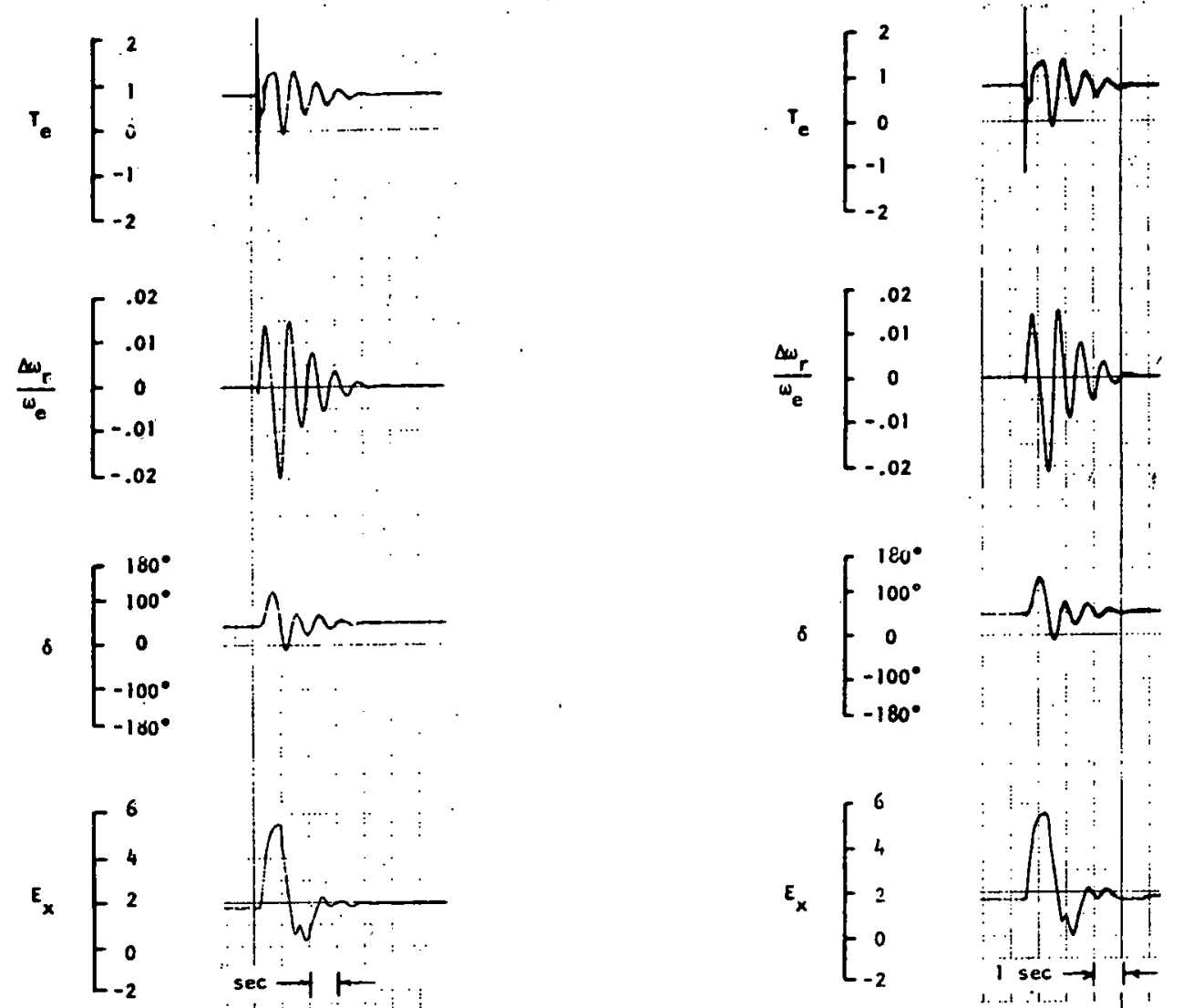

Ex $\left[\begin{array}{c}6 \\ 4 \\ 2 \\ 0 \\ -2\end{array}\right.$

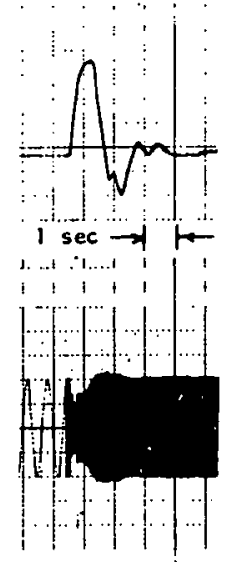

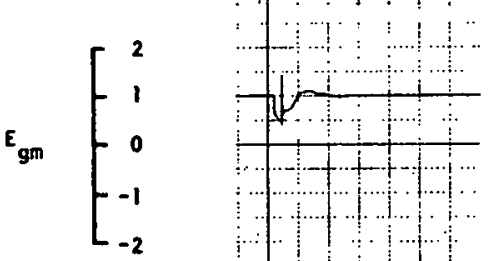
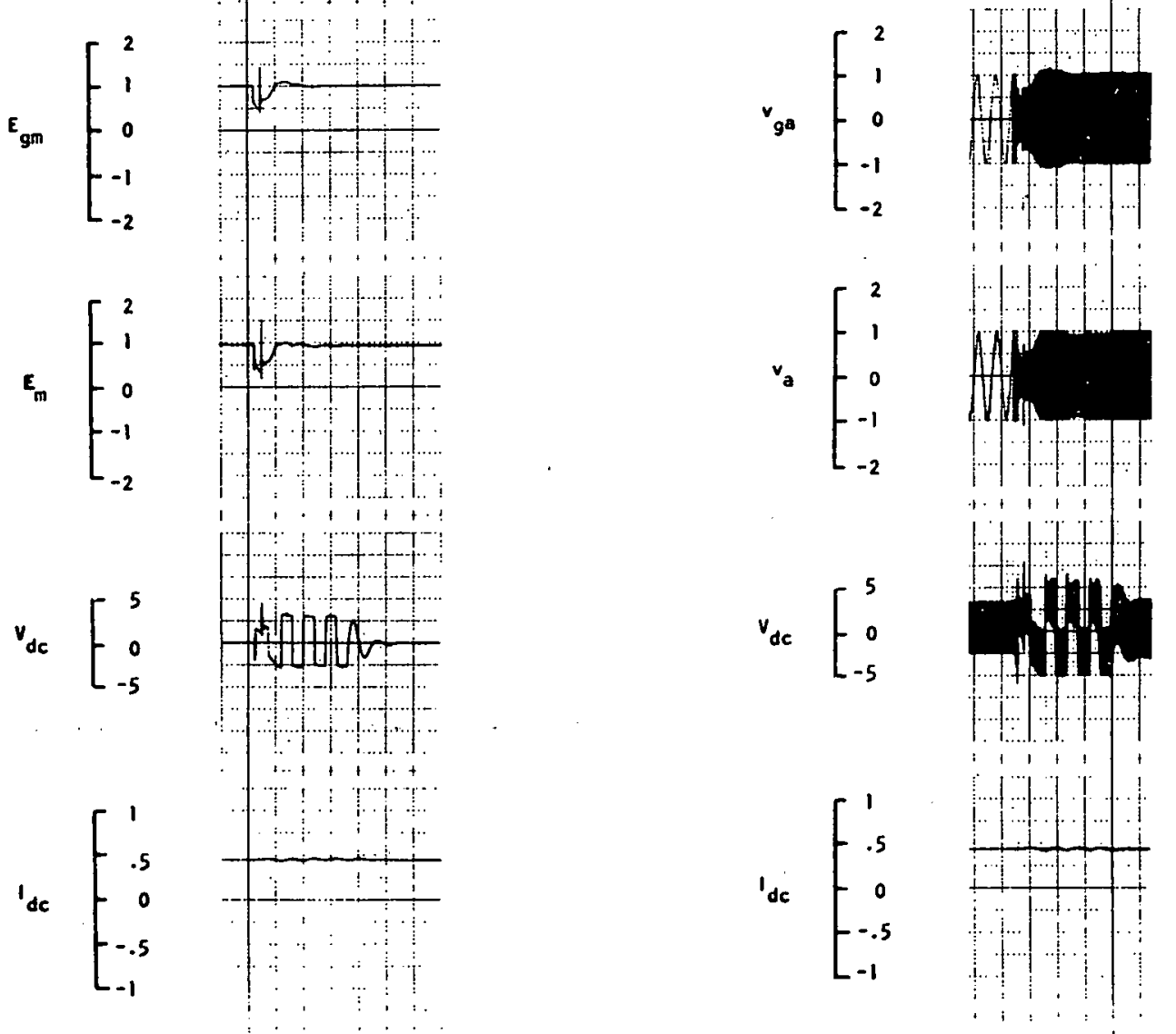

Fig. 1.7 Fault Response of Nominal System with Modulated 70 MW IC Unit, Leading PF: (a) Simplified Model, (b) Detailed Simulation. 

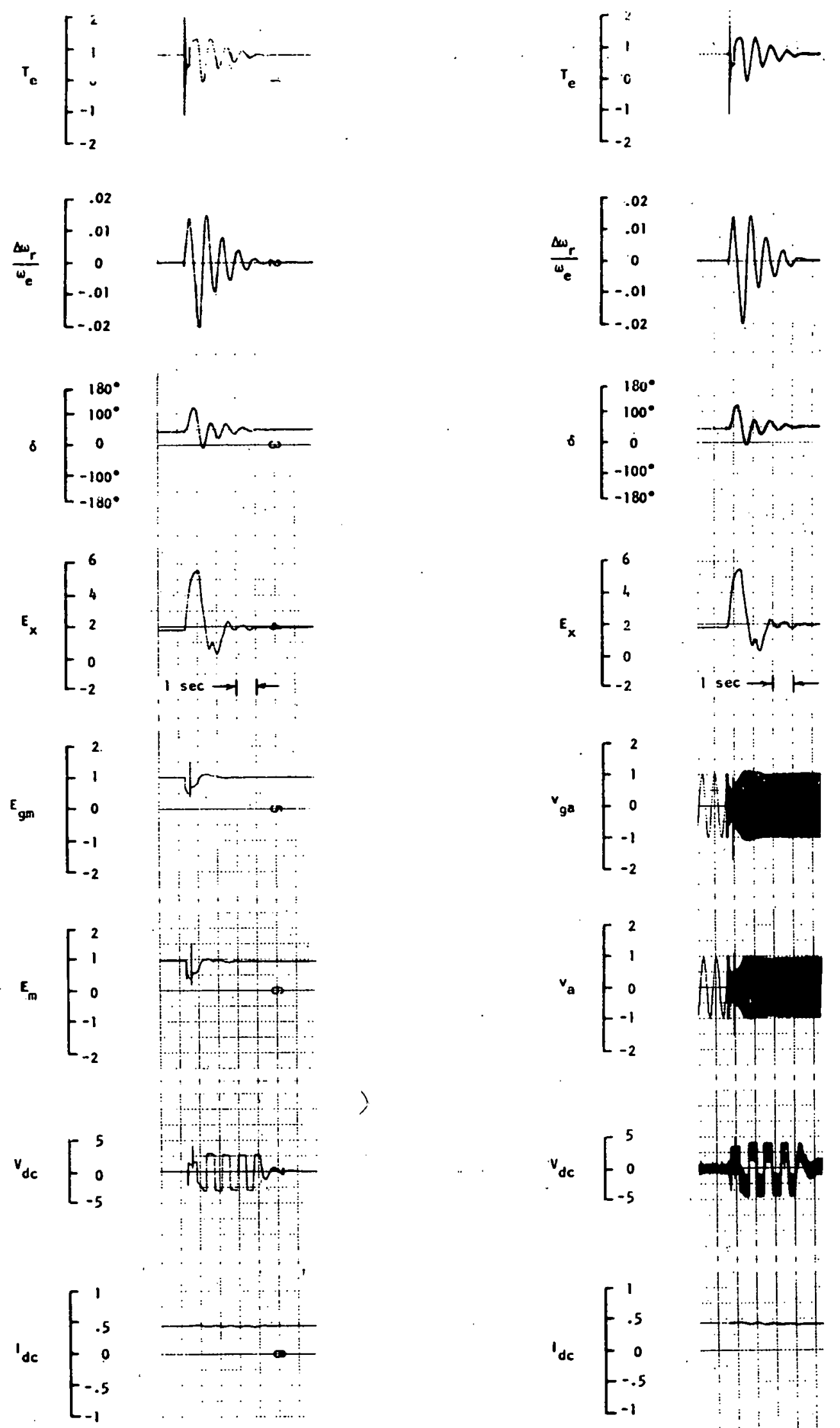

Fig. 1.8 Fault Response with 70 MW IC Unit and $\alpha_{0}=25^{\circ}$, Lagging PF: (a) Simplified Model, (b) Detailed Simulation. 
i. $\left[\begin{array}{c}2 \\ -1 \\ -2\end{array}\right.$

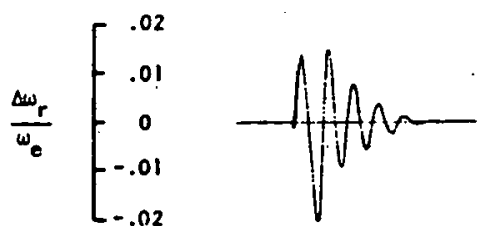

$\delta\left[\begin{array}{cc}180^{\circ} & \\ 100^{\circ} & \\ 0 & \cdots \\ -100^{\circ} & \vdots 00^{\circ}\end{array}\right.$

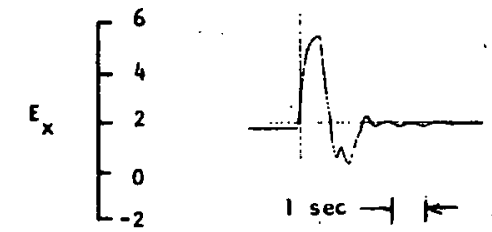

$E_{g m}$

$E_{m}\left[\begin{array}{r}2 \\ 1 \\ 0 \\ -1 \\ -2\end{array}\right.$

$v_{\text {dc }}\left[\begin{array}{r}5 \\ 0 \\ -5\end{array}\right.$

Idc $\left[\begin{array}{c}1 \\ .5 \\ 0 \\ -.5 \\ -1\end{array}\right.$ $\left[\begin{array}{r}2 \\ 1 \\ 0 \\ -1 \\ -2\end{array}\right.$

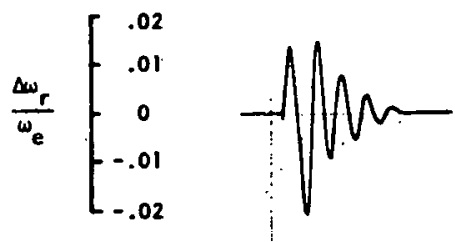

$\delta\left[\begin{array}{cc}110^{\circ} & \\ 100^{\circ} & \\ 0 & \vdots \\ -100^{\circ} & j \\ -180^{\circ} & \vdots\end{array}\right.$

Ex $\left[\begin{array}{c}6 \\ 4 \\ 2 \\ 0 \\ -2\end{array}\right.$

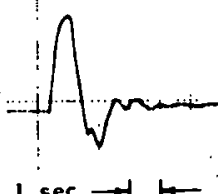

$v_{9 a}\left[\begin{array}{c}2 \\ 1 \\ 0 \\ -1 \\ -2\end{array}\right.$

va $\left[\begin{array}{r}2 \\ 1 \\ 0 \\ -1 \\ -2\end{array}\right.$

$v_{d c}\left[\begin{array}{c}5 \\ 0 \\ -5\end{array}\right.$

$1 \sec \rightarrow$

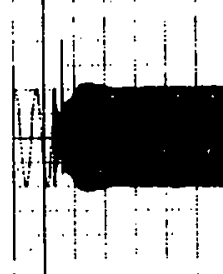

Idc $\left[\begin{array}{c}1 \\ .5 \\ 0 \\ -.5 \\ -1\end{array}\right.$

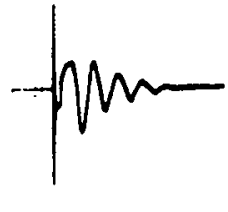




\section{SECTION 2}

POWER SYSTEM IDENTIFICATION

This section of the progress report concerns identification of power system electromechanical models from system measurements, with only normal load variation as a disturbing input.

\subsection{Hardware Nolse Generators}

A final step has been taken to achieve adequate noise generator availability for analog simulations. Eight DIBN generators have been constructed from TTL logic packages and installed in an analog console. These generators repeat after 65,535 binary outputs. This addition to the system facilitates the identification algorithm, as the digital computer no longer has to do noise generation, as well as identification, duty.

\subsection{Least Squares Estimation}

Maximum l kelihood estimation is apparently capable of estimating system parameter values in the problem of concern here. This has been corifirmed in the hybrid computer laboratory at Purdue and elsewhere, although it is not clear whether other investigators have employed a detalled system model to generate the time series data.

This type of estimation presents a tremendous computational load. 0ther types of estimation are under study in an effort to reduce the amount of computation.

It was thought that a least-squares estimation procedure, together with use of the structural properties of the system, would lead to an efficient estimation scheme. This implementation.would:essentially require estimation 
of the ARMA parameters of a system driven by white noise. Sequential leastsquares estimation of the parameters of an AR process is easlly accomplished with the computational aid of the matrix inversion lemma. This was implemented in the hybrid laboratory and was quite successful on example problems. Estimating MA parameters as well is more difficult.

One procedure for estimating both $A R$ and MA parameters involves an inltial estimate the process parameters as AR but of higher order than indicated by physical knowledge of the system. This is a "non-parsimonious" system representation (Box and Jenkins, Time Serles Analysis: Forecasting and Control). The scheme is workable if the higher order AR parameters rapidly converge to zero. Unfortunately, this scheme does not appear to be practical for power system electromechanical dynamics; convergence of the AR representation is too slow.

Two well known identification texts (Graupe, Identification of Systems, and Lee, Optimal Estimation, Identification, and Control) claim that the $n$ AR parameters of an ARMA $(n, m)$ process can be estimated by standard on line least squares techniques if only every $(m+1)$ th sample is used in the estimation. This turns out to not be true because although the residual vector then has uncorrelated elements, there is still correlation between the residuals and the measurements ( $i . e .$, least square estimation of $x$ in $A x=b$ is not possible when elements of $A$ and $b$ are correlated.)

\subsection{The Yule Walker Equations}

Direct least-squares estimation of parameters does not appear to be possible for power system electromechanical dynamics. An investlgation of the Yule-Walker equations is in progress. These equations allow calculation of the $n+m$ parameters of an ARMA $(n, m)$ process from the first $n+m$ terms of the 
system output autocorrelation function. This autocorrelation function is easily estimated from a time series of the system output. Tests on single output systems show the method to be workable, but the details of its use on a multiple output system (proper canonical forms, etc.) have not yet been es tabl I shed. 


\section{SECTION 3}

\section{EQUIVALENT SYSTEM MODEL FOR BPA INDUCTOR- CONVERTER DAMPING STUDIES}

Preliminary studies involving the comparisons of the response of the $A C$ Intertie current predicted by an equivalent representation of the BPA system with that obtained from the actual system have been conducted: It appears that the BPA equivalent can be made to portray the response of the AC Intertie during the application and removal of the Dynamic Brake with reasonable accuracy. The operation of the IC unit has been incorporated in this representation and studies have been performed to determine the ability of this unit to damp $A C$ Intertie current oscillations. At this time the compensator gain as determined from earlier studles using. the transfer function approach appear to be larger than that necessary when using the equivalent system representation. This discrepancy may be due to an error in the simulation of the equivalent system.

\subsection{BPA Equivalent System Representation}

The one-line diagram shown in Fig. 3.1 is the BPA equivalent system furnished by C.W. Taylor. This system was given in Fig. 1.4-1 of Progress Report C00-4206-4 dated April 1978. The system represented in this preliminary study is shown in Fig. 3.2. In particular, three of the four equivalent machines were represented in detall with the machine at Sylmar represented as an infinite bus $(1.0 \mathrm{pu}$ voltage). The following parameters for the three equivalent machines (10,000 MVA base) were used in the study.

The parameters for the generator set-up transformers $\left(r_{t}\right.$ and $\left.x_{t}\right)$ are also given. 


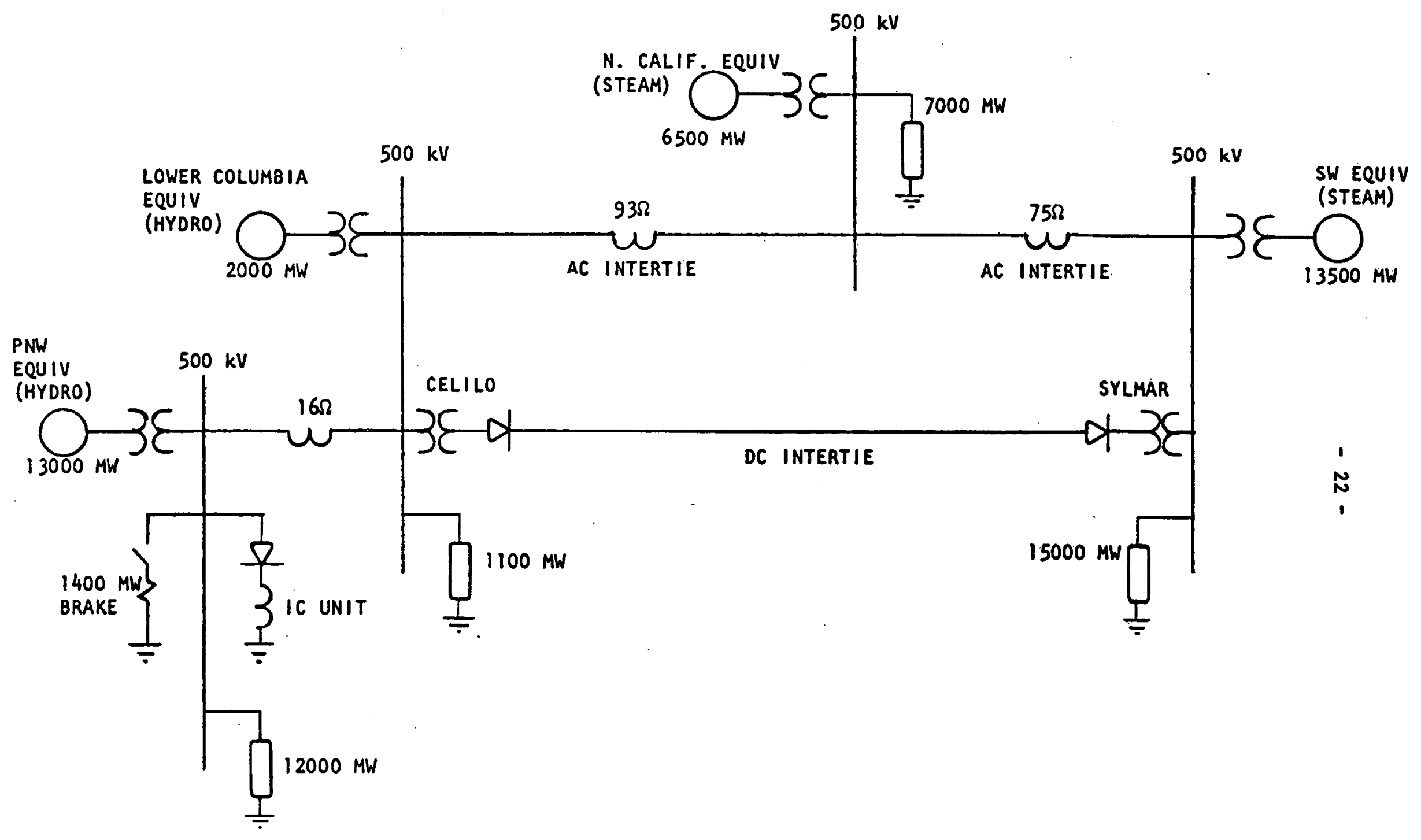

Fig. 3.1 - BPA equivalent system. 


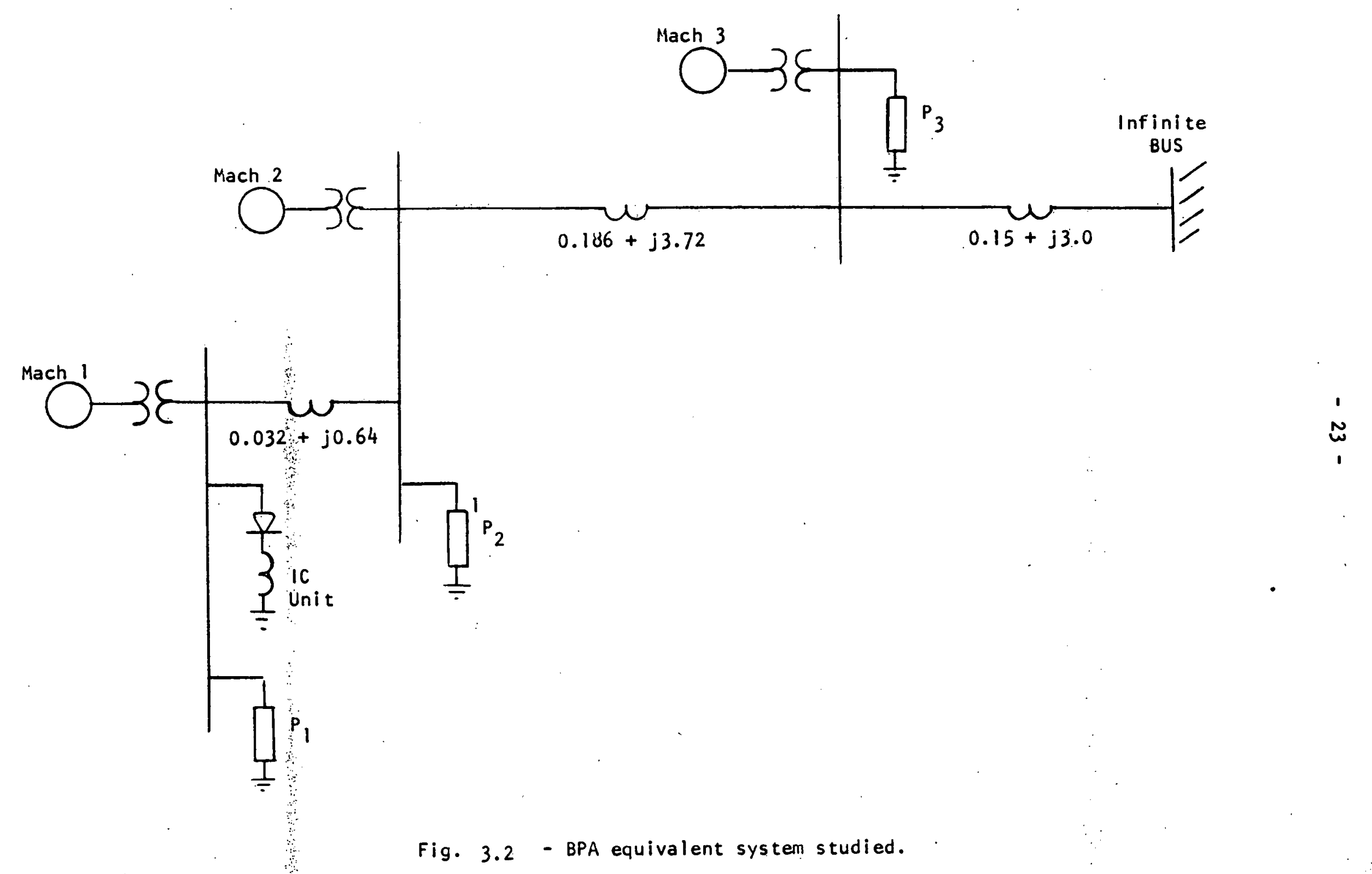




\begin{tabular}{|c|c|c|c|}
\hline Parameter. & $\begin{array}{l}\text { Mach I } \\
13,000 \mathrm{MW} \\
\text { Hydro }\end{array}$ & $\begin{array}{l}\text { Mach } 2 \\
2000 M W \\
\text { Hydro }\end{array}$ & $\begin{array}{l}\text { Mach } 3 \\
6500 \mathrm{MW} \\
\text { Steam }\end{array}$ \\
\hline r. & 0.0038 & 0.025 & 0.0031 \\
\hline$x_{\ell}$ & 0.154 & 1.0 & 0.138 \\
\hline$x_{d}$ & 0.885 & 5.75 & 1.69 \\
\hline$x_{d}^{\prime}$ & 0.285 & 1.85 & 0.354 \\
\hline$x_{d}^{\prime \prime \prime}$ & 0.185 & 1.2 & 0.185 \\
\hline$x_{q}$ & 0.577 & 3.75 & 1.66 \\
\hline$x_{q}^{\prime \prime}$ & 0.262 & 1.7 & 0.231 \\
\hline$T_{d}^{\prime}$ & 1.8 & 1.8 & 1.1 \\
\hline$T_{d}^{\prime \prime}$ & 0.035 & 0.035 & 0.035 \\
\hline$T_{\text {do }}^{\prime}$ & 5.6 & 5.6 & 5.6 \\
\hline$T_{q}^{\prime \prime}$ & 0.035 & 0.035 & 0.035 \\
\hline H & $5.2 \mathrm{~s}$ & $0.8 \mathrm{~s}$ & $2.6 \mathrm{~s}$ \\
\hline$r_{t}$ & 0.00769 & 0.05 & 0.0154 \\
\hline$x_{t}$ & 0.0769 & 0.5 & 0.154 \\
\hline
\end{tabular}

Each machine is equipped with a single time constant voltage regulator $(1.0 \mathrm{sec})$ with a gain of 50 . Provisions are made to represent damping external to the machine for the purpose of duplicating the dampIng observed during the Chief Joseph Dynamic Brake test. The parameters 
(10,000 MVA base) for the transmission lines are shown on Fig. 3.2.

The loads were regulated to give constant power. The load at Chief joseph was represented with provisions to simulate the application and removal of the brake by approprlately changing the value of $P_{1}$. The IC unit was represented by adjusting the reference of this regulated power load thereby changing the load at the Chief Joseph bus in accordance with the ic unit controller. The load $P_{2}$ includes the $D C$ Intertle power which was $1100 \mathrm{MW}$ (export) in order to duplicate the AC Intertie power flow of 1400MW (export) at the time of the brake test.

\subsection{Computer Study-BPA Equivalent System}

The time response of the AC Intertie power or current due to the energization of the Chief Joseph Dynamic Brake is shown in Fig. 3.3. This plot was also given in Fig. 1.3-1 of Progress Report C00-4206-4 dated Aprll 1978. The application of the brake is a $1300 \mathrm{MW}, 0.5 \mathrm{sec}$ power pulse. Two ordinates are given in Fig. 3.3. One for the change in AC Intertie power and one for the charge in the magnitude of the rms AC Intertie current. This curve was furnished by BPA.

The curve given in Fig. 3.4 shows the plot of the magnitude of the AC Intertie current obtained from the computer representation of the BPA equivalent system shown in Fig. 3.2. In this case the brake power was I400MW rather than $1300 \mathrm{MW}$. A comparison of Figs. 3.3 and 3.4 reveals a reasonable correspondance. It is clear that the change of current is plotted in Fig. 3.3, whereas the total current including the initial pretest current is plotted in Fig. 3.4 .

As reported in Progress Report C00-4206-4, the compensator was designed for the IC unit using a transfer function approach to represent the 


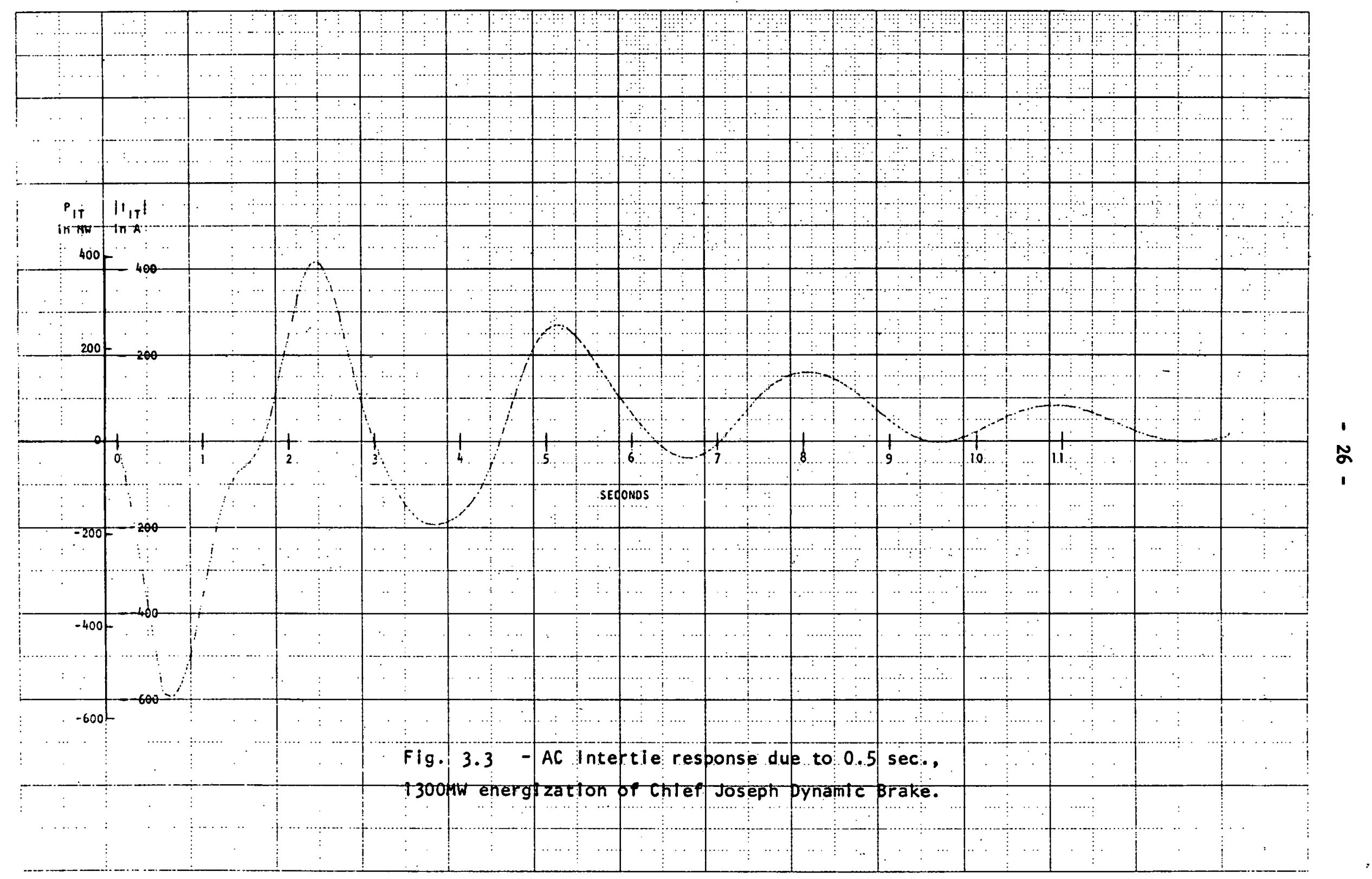




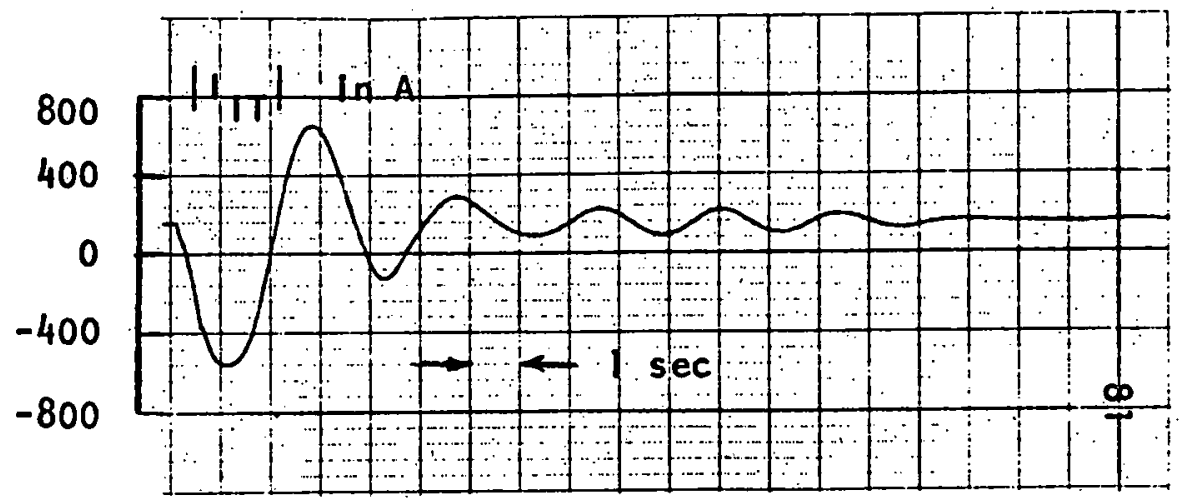

Fig. 3.4 - Magnitude of AC Intertie current during 1400MW brake test-BPA equivalent system.

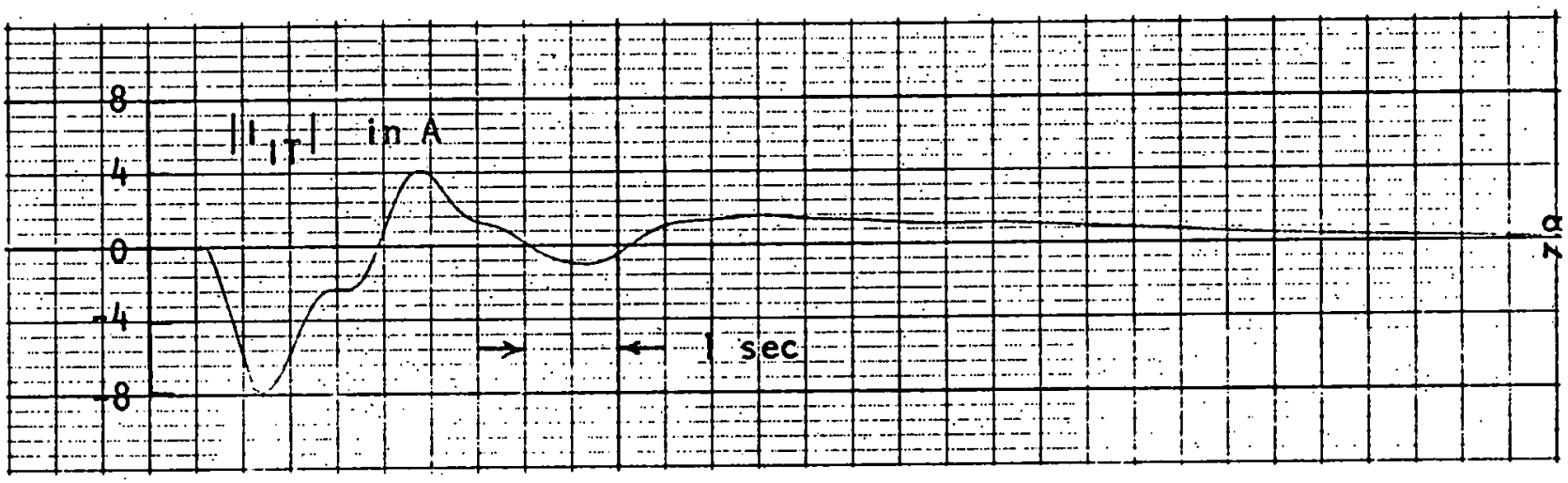

Fig. 3.5 - Magnitude of AC Intertie current during a 10MW brake test-transfer function approach with IC unit in service.

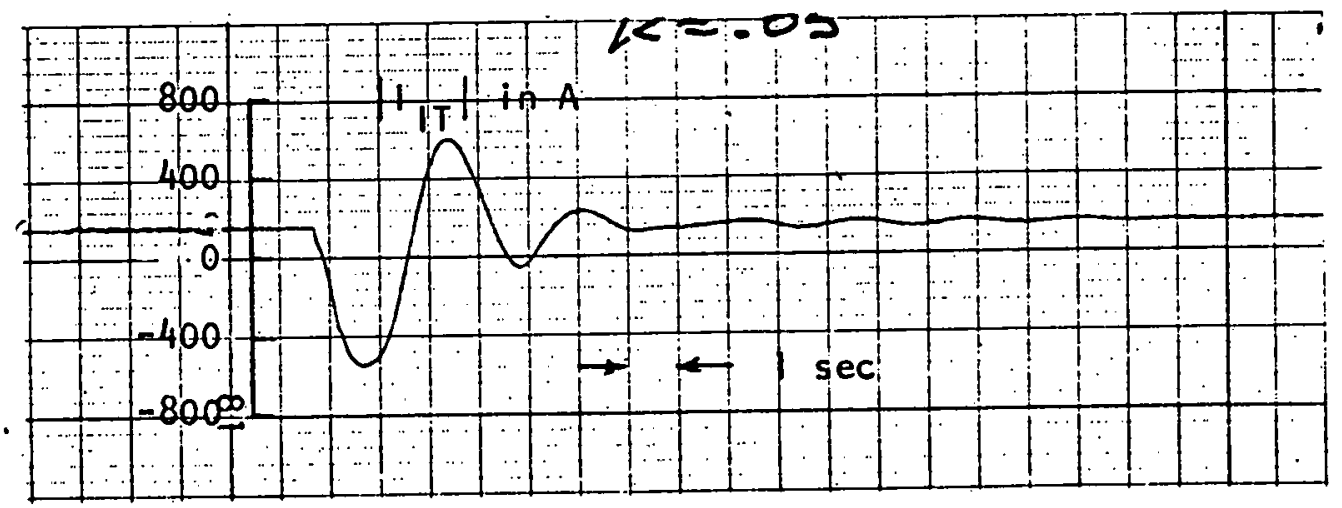

Fig. 3.6 - Magnitude of AC Intertie current during 1400MW brake test-BPA equivalent system with IC unit in service. 
power system. The response of the AC Intertie current to a lOMW brake application for $0.5 \mathrm{sec}$ obtained using this approach to design the controller gain is shown in Fig. 3.5. Since in the transfer function approach the system is assumed linear, this response would be identical in waveform to that for a brake application of $1400 \mathrm{MW}$.

A representation of the IC unit was incorporated into the BPA equivalent system shown in Fig. 3.2. The response of the AC Intertie current with a compensator gain of 10 times less than that used in Fig. 3.5 is shown in Fig. 3.6. Since this plot is similar in waveform to that shown in Fig. 3.5 it is clear that an error exists. At this time it appears that the error is in the computer simulation, nowever, it is not readily evident.

\subsection{Conclusions and Work Schedule-BPA Project}

It appears that the BPA equivalent system can be made to response to the application of the Chief Joseph Dynamic Brake similar to that of the actual system. Work will continue in an effort to include more detail in the representation; the fourth machine and the dc line may be added if it is felt necessary after consulation with BPA. Of first

- concern, however, is the determination of the reason for the difference in the gain of the compensator (Section 3.2). Once this is resolved work will continue on the development of a more detailed simulation and the nonlinear operation of the IC unit. 